\title{
Effects of Broadband Internet on Studying Habits of the University Students in Pakistan (A Case Study of University of Gujrat)
}

Atiya Dar*

Centre for Media and Communication Studies, University of Gujrat, Gujrat, Pakistan

\begin{abstract}
Utility of broadband internet is consistently on the increase both in amount of its users as well as expand in the activity. This medium serves tremendous functions at a time and transmits information among people and organizations globally. These technological advancements affect the daily routine of people and also converging in culture as a whole. The study is beneficial in this regard; it depicts whether arrival of broadband internet influences the studying behavior of students and how much time they spend with internet. Do they rely on it with comparison of other mediums? Broadband internet sensitizes students about global knowledge and gives opportunity to "click" and explore knowledge. It depends on the students' potential however they use it optimistic or pessimistic way. The main focus of this short paper study is to provide concise information of broadband internet and its impact on students behavior of University of Gujrat Pakistan.
\end{abstract}

Keywords: Broadband internet; Students; Studying habits

\section{Introduction}

Internet is the requirement of time and obligatory for everyone, as a household to office worker. It is an apparatus that turns the world into a global village. Broadband is the best example of technological revolution in internet services. At first glimpse it seems that students misuse this technology but it also helpful in knowledge gaining and developing social skills among them. It makes them responsible and creates analytical skills in their personality so that they create and share knowledge globally. At this time computer and internet technology is the component of university student's education system and has the tremendous influence on their studying habits. Utility of internet is most frequently concerned with college and university students which initiate the research patterns to discover its effect on multiple behavioral perspectives of students. Students are the growing power of a society and their concerns locate the trend, and the growing interest of students towards portable internet devices for the usage of non-stop internet access raised the questions in mind about its optimistic or pessimistic influence on students studying behavior.

\section{Internet}

The internet is a network of computer networks. These networks include computers found in business, universities, libraries, government, media companies, and homes. Internet access has been available in Pakistan since the early 1990s. PTCL started offering access via the nationwide local call network in 1995. By early 2006 internet penetration remained low. But the numbers are growing [1]. Internet provides some of the most effective means of communication, E-mails and instant messages have made the online communication possible. Social networking, blogging websites and online discussion forums have proved, being popular platforms for expression. Over the years the expansion and attractiveness of internet has not been constant but it rapidly increases with the passage of time and never face decline in its growth.

\section{Broadband}

Broadband was first introduced in Pakistan in 1995 by Telstra [Australian Telecom Company] with the design of the repeater huts being done by Design man-an Islamabad civil engineering firm. The first and only official cable internet service was launched in 2000 by a company named World call under the brand name of GO4B. The first DSL service was launched by Micro Net in Islamabad/Rawalpindi in 2002. Pakistan had almost 128 ISPs in 2007 with internet users being concentrated in the areas of Islamabad, Karachi, and Lahore. The broadband penetration during the same period stood at 6.1 percent with $6,000,000$ subscribers of which 80 percent were cable broadband internet subscriber, 18 percent were DSL subscribers and 2 percent were satellite and wireless broadband subscriber. Today broadband is offered in Pakistan from 512 KBIT/S 1012 MBIT/S in all major cities. Currently Pakistan has 128,680 DSL Subscribers in the country. The big DSL provides are PTCL and link dot net. Other small DSL providers are micro net, cyber net, max com, multi net, world call, brain net and comates [1]

\section{Literature Review}

Research the effects of social media on students revealed that social networking sites are the tools of mainstream internet. In this concern social media containing the sites as Facebook, Twitter, Youtube, Myspace, Linkedin and Blogs. Students are affected by social media; no doubt these sites have been the crucial source of entertainment and a good way to release the pressure of students. On the other hand, moreover it affects the grades of college students pessimistically. It also point toward, that an approach is requisite to improve the balance relationship among social media and academic study [2].

Due to the amplified recognition of internet, economists and professors are curiously involve in discovering the fact that whether the grades of students are being affected by quantitative tendency of time is consumed with these sites. According to the study of J. Mathew

*Corresponding author: Atiya Dar, Centre for Media and Communication Studies, University of Gujrat, Gujrat, Pakistan, Tel: 0343-6729510, E-mail: Atiya.dar@uog.edu.pk

Received May 04, 2013; Accepted May 21, 2013; Published May 28, 2013

Citation: Dar A (2013) Effects of Broadband Internet on Studying Habits of the University Students in Pakistan (A Case Study of University of Gujrat). J Mass Communicat Journalism 3: 154. doi:10.4172/2165-7912.1000154

Copyright: @ 2013 Dar A. This is an open-access article distributed under the terms of the Creative Commons Attribution License, which permits unrestricted use, distribution, and reproduction in any medium, provided the original author and source are credited. 
stated that "with smart phones being able to access the internet and have applications of social networking, many are concerned about how smart phones with social networking applications will affect student's grades". Maximum utility of social networking tools like Facebook retender a pessimistic relationship between the consumption of social network on the students grades.

Extensive usage of internet and the particularly use of Facebook by students with extraverted personalities escort towards the poor academic performance. Students' cognitive absorption with facebook is synchronized only by their strength of will and personality qualities, which determine how much time they spend on facebook [3]

Internet has become an indispensable tool in our society for the purpose to gain information. Variety of people utilizes it according to their requirements with time availability. It has dual functions in our society as the source of entertainment also students use it for academic purposes. 51.4\% ratio of people use internet for multiple objectives in Pakistan. People depend on internet to gain information for academic facilitation than for any other reason. More students use internet for the educational purposes as compare to computer professionals and teachers [4].

College students use internet most frequently and heavily as compare to the general population. Use of internet is the ingredient of student's daily routine. They are grown up with technological advancement. Computer and internet are included into their daily communication lifestyle and it is ordinary and accessible as the telephone or television. According to the American college students, internet has increased their education in order to the availability of online libraries, to do research, online communication and discussion with classmates and professors. Apart from the academics, internet has been changed their social life as well [5].

Google generation has the access of cheaper and faster speed internet and smart phones make capable the young adults in adoption of social networking sites. This reduces the trend of paper-based communication. The study also ascertains social networks sites most preferred by South African students, and SNS culture rapidly growing among them. Another important indicator of the study that, use of internet and SNS perpetually augment the progress of studies (from undergraduates to post graduates) [6].

High school students use different SNS and it influenced their academic performance inconclusively. Female student's ratio is more, to participate in social networking as compare to male students but still they have higher grades than males. This study has publicized the fact that social networking can have a pessimistic impact on study habits and completion of homework assignments, but there was not a dire difference between students who spend more time and those who do not [7].

In the age of technology internet is a valuable apparatus for every field of life. As far as concerned it is not only vital for business concern but important for the educational point of view and has unpredictable benefits for students. Recently internet is the best source to enhance the skills and capacity of students. Internet playing the role of a leader which assist the students to step forward in their professional life. Students with the increase utilization of internet for the sake of their studies, information and knowledge gaining across the world contain high CGPA [8].

This study depicts the co-relation of internet usage and impact on academic performance from the Nigerian university undergraduates.
Results show the positive relationship existing among the internet usage and academic achievements. Internet has been pretending the influence on student's academic performances both at local and international level [9].

\section{Theoretical Frame Work}

Uses and gratification approach is concerned with this research. Uses and gratification focuses audience members are not passive and do not accept the contents whatever media transmit. They select media according to their choices and needs. Consumers of media have a composition of motivating needs seek to satisfy the needs they select or reject any kind of media and its contents through different kinds of experience. Some media selections may indeed be made on the basis of need gratification, other kinds of exposures are based on personal, social, cultural, and emotional considerations that guide people in what they choose to consume from the media [10].

\section{Statement of problem}

The basic aim of the study is to discover the impact of broadband internet on studying habits of students. And study also Whether or not the extensive use of relatively cheap broadband internet is affecting studying habits of UOG students negatively or positively.

\section{Research question}

- Whether and to what extent broadband internet has affected the studying habits of UOG students?

- What is the amount of time students spend utilizing broadband internet in a day?

\section{Methodology}

In this research, survey method has been used to collect the data that is quantitative in nature. Stratified sampling is used, strata's divided on the basis of gender, male and female. Sample is proportionate in nature. 200 respondents are measured from social and basic science disciplines. Instrument of questionnaire has been used and all the questions put an effort to measure the effects of broadband internet on the studying habits of UOG students.

\section{Findings and interpretation}

Findings, most significant part of the study that point towards the results of the complete study with statically presented graphs and charts. It is the essence of whole research. Researcher illustrates

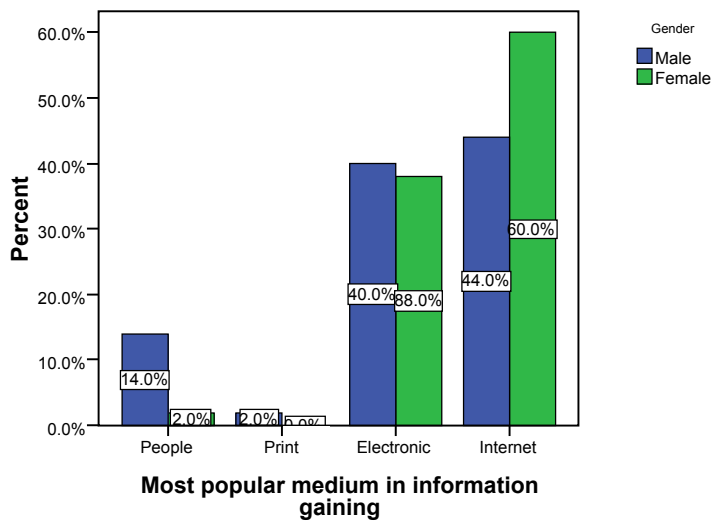

Figure 1: Firstly this graph shows internet as the most popular medium in information gaining among students with the highest ratio. 


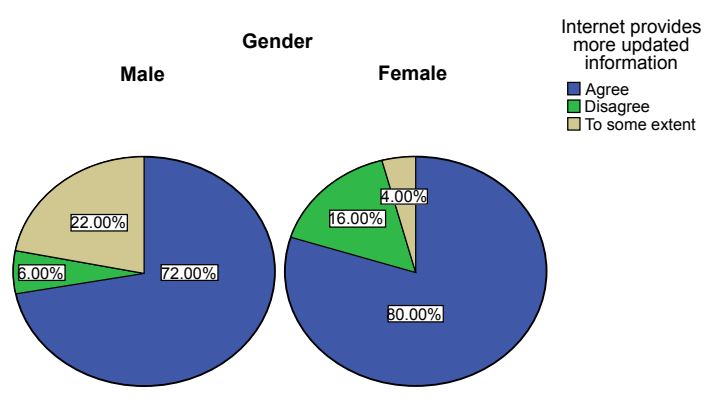

Figure 2: This graph illustrates that students agree with the phenomena that internet is a source of providing more updated information.

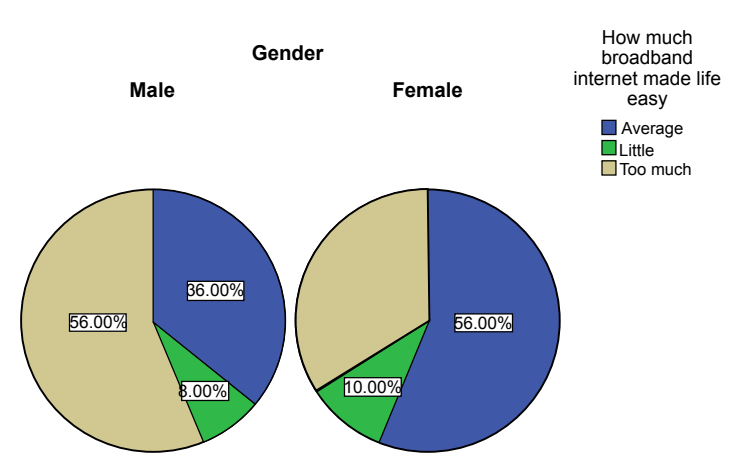

Figure 3: Results of this question quantify that broadband internet make student's life easy.

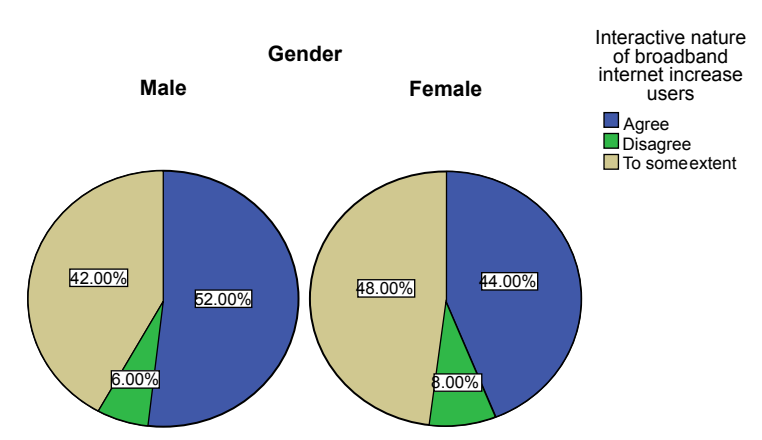

Figure 4: Students agree with this assumption that interactive nature of broadband internet is a reason for increasing number of users.

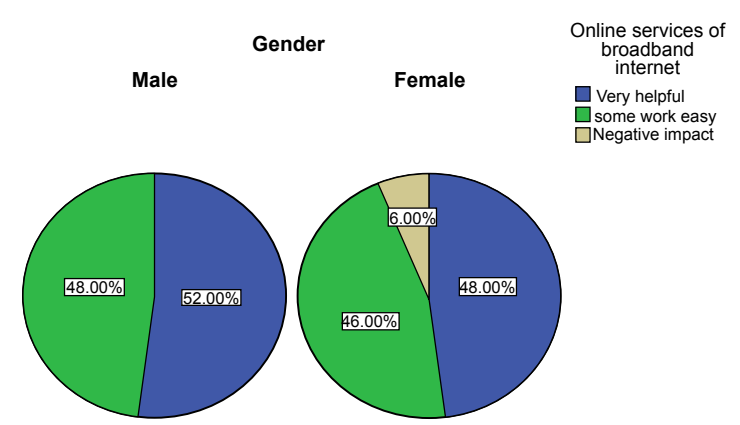

Figure 5: One very imperative concept that broadband internet switched every service online which made some work easy and it's helpful in nature for students.

the respondents view point with mathematical percentage. All the responses of survey questions explained in detail (Figures 1-10).

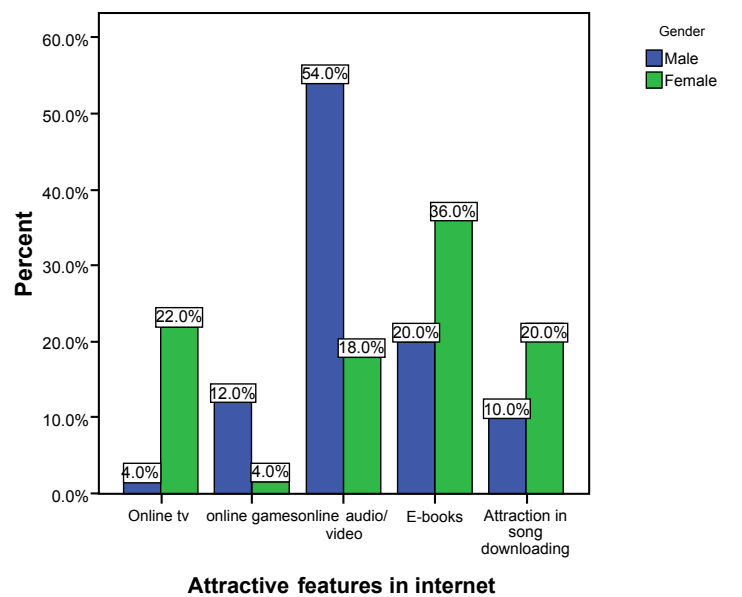

Figure 6: For student's attractive features in internet is online TV watching, online games, audio video communication, E-books and song downloading, but E-books and audio video communication is priority choices with highest percentage among students.

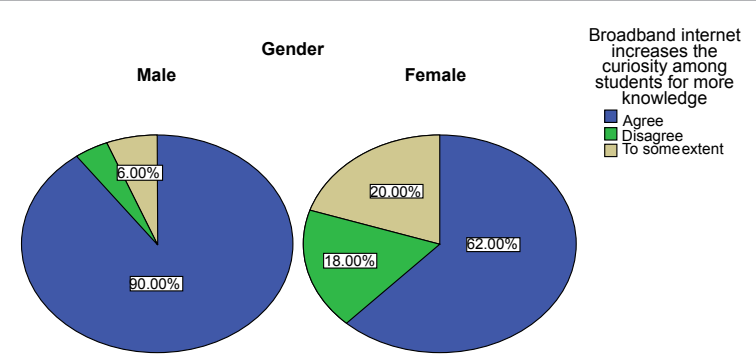

Figure 7: Respondents are concur that broadband internet is responsible in creating curiosity among them to seek more knowledge.

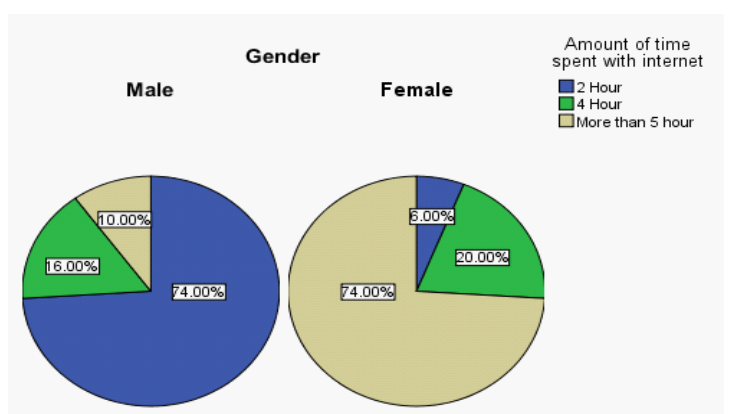

Figure 8: $74 \%$ student respondents utilize services of broadband internet more than 5 hours a day.

\section{Discussion of Results}

This study is just about to scrutinize the effects of broadband internet on students studying habits. More likely students depend on broadband internet for the sake of information seeking; they spend more time with internet which augments a quest for more knowledge seeking by given unlimited usage to click the hyperlinks for depth study. So all supportive questions facilitate the key research question and unable to understand students studying habits concerned with the services of broadband internet.

\section{Conclusion}

Hypothesis of the study has approved that arrival of broadband 


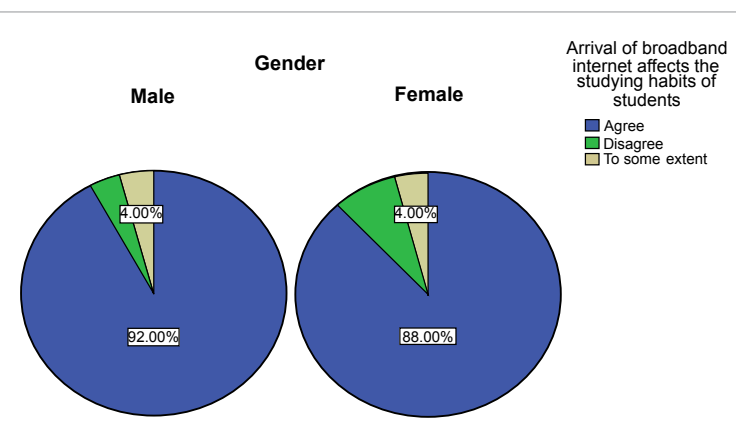

Figure 9: Students are in agreement with the ratio of $88 \%$ that arrival of broadband internet is accountable to affect their studying habits.

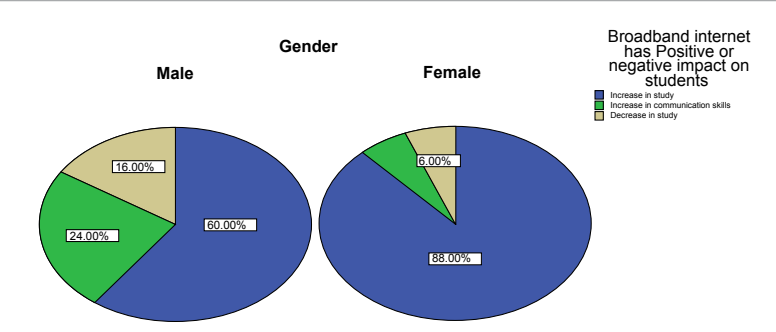

Figure 10: Students consent that broadband internet effect their lives in optimistic way. It makes a difference and increases their studying habits and then amplifies their communication skills.

internet effects the studying habits of UOG students in an optimistic way. Broadband internet facilitates them in information seeking and has been boost up their studying habits. They prefer to spend their time with internet as compare to any other medium. Majority of students consume internet more than 5 hours a day and this ratio depicts the importance of this medium. Broadband internet provides them easy access towards online data searching and students can go into depth study by click the links available for detailed information.
According to the results, internet is the most popular medium in information gaining among UOG students. Internet provides them more updated information than any other medium. They illustrated that broadband internet made their lives easy, offering unlimited features with affordable price. Interactive nature of broadband internet is a reason for increasing the users of broadband internet day by day. Portable broadband internet device is persuading in adoption of laptop technology. Internet converted its services from dial-up to broadband connections. It is responsible to convert almost every service online. It is very helpful for the students of UOG. Broadband internet made communication and interaction more strong and frequent than ever before. Majority of students utilize broadband internet due to audio video communication and for information gaining.

\section{References}

1. Shahid MI (1991) Mass Communication.

2. Wang Q, Chen W, Liang Yu (2011) The effects of social media on college students. MBA student Scholarship Paper 5.

3. Sana R, Moez L, Esmail SS (2011) Impact of facebook usage on students. Academic achievement.

4. Shahzad Ali, Rooh-e-Aslam (2008) A Study about the Uses of Internet in Pakistan. European Journal of Social Sciences 6: 4.

5. Steve J (2002) The Internet Goes to College How students are living in the future with today's technology. Pew Internet \& American Life Project.

6. Richard S, Robert R, Nkosinathi S (2012) Social networking habits among students. African Journal of Business Management 6: 578-586.

7. Flad, Kaitlyn (2010) The Influence of Social Networking Participation on Student Academic Performance Across Gender.

8. Awais, Bilal, Usman M, Waqas M Sehrish Impacts of Internet Usage on Students' Academic Performance (CGPA).

9. Peter MO (2010) Internet usage and students academic performance in Nigeria tertiary institutions: a case study of University of Maiduguri. Academic Research International 2: 3 .

10. DeFleur (2010) Mass communication theories, explaining origins, processes and effects. Pearson. 